\title{
Speed of Adjustment and Infraday/Intraday Volatility in the Italian Stock and Futures Markets
}

\author{
Pietro Gottardo \\ Dipartimento di Ricerche Aziendali, Facoltà di Economia, Pavia, Italy \\ E-mail:pgottardo@eco.unipv.it \\ Received July 15, 2011; revised August 19, 2011; accepted September 1, 2011
}

\begin{abstract}
We estimate the speed of adjustment of prices to value changes in the Italian stock and futures markets using variances in different return intervals. The paper presents evidence that an assumption of linearity for the relationship volatility-time is untenable when intraday and infraday data are used jointly. Prices adjust to new information within three days, but the process is complex with evidence of overshooting and divergent movements in the smaller return intervals. Firms behave differently according to their inclusion or exclusion from the MIB30 index. The speed of adjustment is strongly related to firm-specific characteristics and the log of capitalization explains some of the cross-sectional variability in the adjustment coefficients for most of the return intervals.
\end{abstract}

Keywords: Speed of Adjustment, Overshooting, Intraday returns, Stock Index Future

\section{Introduction}

The growing body of evidence on stock returns predictability and overreaction challenges the traditional efficiency view that stock prices reflect fully and quickly all the relevant information. Event-based return predictability, long term reversals and short term momentum, excessive stock prices volatility relative to fundamentals are some of the findings of a large number of empirical works in different areas, countries and time periods. Daniel-Hirshleifer and Subrahmanyam [1] cite a large sample of the relevant literature on these topics.

There is disagreement over the interpretation of this evidence. The anomalies may be considered normal chance deviations from the fundamental efficiency law as suggested by Fama [2], but the regularity and dimension of these phenomena cast some doubt on the appropriateness of this hypothesis. An alternative explanation is that many empirical regularities represent variations in rational risk premia, even if this requires an asset pricing model with extreme variability in marginal utility across states and has other undesirable implications.

Daniel-Hirshleifer and Subrahmanyam [1] suggest a psychological model based on imperfect rationality, in particular they construct their model on two well-known psychological biases: investor overconfidence about the precision of his private information, and biased self-at- tribution which causes individuals to strongly attribute events that confirm the validity of their actions to high ability and events that disconfirm the action to external noise or sabotage.

Another stream of literature suggests instead a lagged adjustment of security prices to new information. PatellWolfson [3] and Hasbrouck-Ho [4] are just two examples of empirical studies showing that prices take time to adjust to news. Patell-Wolfson [3] examine intraday price changes associated with earnings announcements. From a theoretical perspective the derivation of a partial price adjustment model in security markets, showing that this is the result of optimizing behavior by market makers is due to Garbade-Silber [5,6]. Goldman-Beja [7], Amihud-Mendelson [8], and Damodaran [9] describe a return process that can be applied to portfolios and index futures as well as single stocks which permits the derivation of a measure for the price adjustment coefficient. The model derived in Amihud-Mendelson [8] and in Damodaran [9] distinguishes between observed prices and intrinsic value of a stock, measuring a finite speed of adjustment of prices to value changes using the information in various return intervals.

The screening among all these models is just an empirical matter, only the real behavior of prices in security markets can shed some light on the subject. In what follows we use Damodaran adjustment model in the correct 
form derived by Brisley-Theobald [10], with a significant difference in his assumption with respect to the relationship between time and volatility, to analyze the price adjustment in the Italian futures and stock markets. The primary contribution of this paper is a refinement of the model in Damodaran [9] to account for the estimation of adjustment coefficients using together intraday and infradaily data and its application to a new data-set to disentangle the relative merits of the above models. We calculate returns and variances over non-overlapping periods and estimate the price adjustment coefficients at intraday intervals of five, fifteen, thirty, sixty minutes, two, four, and eight hours and at infraday frequencies from one to ten days. The relationship between time and volatility is a key empirical problem, usually solved assuming the linearity of this relationship. Using only daily returns a linear approximation could be reasonable but not with the inclusion of intraday returns. As we show in section 3 the inclusion of both infraday and intraday measurement intervals has a severe impact on the linearity of the relationship, so that the usual assumption is untenable using datasets and models that take into account jointly information on the volatility within a trading day (intraday intervals) and across trading days (infraday intervals). Section 2 presents the price adjustment model used. We analyze in section 3 the return behavior of the Italian stock index and stock index futures together with a selection of single stocks. The choice is useful to screen possible differential adjustment processes for the index, futures and the single securities as half of this sample is given by stocks not included in the index over which the futures contract is designed. Section 4 concludes with a discussion of our results and some policy implications about the efficiency and liquidity improvement of the assets negotiated in these markets.

\section{Price-Adjustment Model}

The price adjustment model of Amihud and Mendelson [8] distinguishes between the intrinsic value of a stock, futures or portfolio, $V_{t}$, and the observed price, $P_{t}$.

A generalization of their interpretation of this model allows for market-related, specific information and noise to be reflected in the return process, resulting in an imperfect (partial or lagged) price adjustments to value changes, but also for overshooting phenomena (a morethan-perfect adjustment) or divergence from value. The basic model is

$$
P_{i, t}-P_{i, t-1}=g\left[V_{i, t}-P_{i, t-1}\right]+u_{i, t}
$$

where $g$ represents the speed of price adjustment: $g=1$ implies a full and almost immediate (as the one period lag can be small as you like) adjustment of prices to every change in value, $g>1$ represents a tendency for the asset to overreact to news affecting its value, whereas $0<g<1$ includes all cases of partial and lagged adjustment. Last but not least for importance is the case when $g<0$ that implies price divergence from the intrinsic value.

The possibilities of overreaction or divergence from value have been totally neglected in the theoretical developments of this model by Amihud-Mendelson [8] and Damodaran [9] but given the results in DeBondt-Thaler [11] and the implications of behavioral or psychological models for the price generation process we believe that a careful investigation is called for. The noise term, $u_{i, t}$ in Equation (1) is determined by information and markets structure related factors such as liquidity trading, noise, bid-ask spread. It is assumed to be a sequence of i.i.d. random variables with zero mean and finite variance, $\sigma_{i}^{2}$ and independent across stocks.

To derive a measure of $g$, Damodaran [9] uses the variances in different return intervals that can be written as

$$
\operatorname{Var}\left(R_{i, j t}\right)=\frac{g_{i, j}}{2-g_{i, j}} j v^{2}+\frac{2}{2-g_{i, j}} \sigma^{2}
$$

where $\operatorname{Var}\left(R_{i, t}\right)$ is the variance for the observed returns assuming $j$ as measurement interval, while $g_{j}$ is the adjustment coefficient measured for the same j-interval returns, and $v^{2}$ is the variance of the intrinsic value process.

A restrictive by-product of the original assumptions of this model is that $v^{2}$ is linear in $\mathrm{j}$, as $\left\{V_{t}\right\}$ is an i.i.d. random variable and the intrinsic variance and noise processes are assumed to be independent. This assumption is apparently innocuous given that a linear relationship between volatility and calendar time is almost standard in many areas of research in finance. Unfortunately even with daily data it is a well known and established result that a linear relation between volatility and time is at best a first approximation as weekends and other non-working holidays have a less than proportional effect on stock volatility. The problem is of great concern here because our intention is to measure the price adjustment coefficients using together intraday and infradaily data, see for instance Amihud-Mendelson [12], Amihud-Mendelson and Murgia [13], and Gottardo [14]. To the degree that this hypothesis is violated, the model estimates of $g_{j}$ will be grossly flawed. We suggest to replace Equation (2) with the following more general formulation:

$$
\operatorname{Var}\left(R_{i, j t}\right)=\frac{g_{i, j}}{2-g_{i, j}} f(j) v^{2}+\frac{2}{2-g_{i, j}} \sigma^{2}
$$

analyzing three different forms for the relationship be- 
tween intrinsic volatility and return measurement inter- val:

$$
f(j)=\left\{\begin{array}{lc}
j & 1 \leq j \leq k \\
j d & 1 \leq j \leq k \text { and } d=1 \text { for } 1 \leq j \leq l d=1 / \lambda \text { for } l<j \leq k \\
\text { empirical average relation between time and volatility }
\end{array}\right.
$$

The first one is the usual assumption of linearity in variance while the second form give us some freedom particularly useful if we choose the point of discontinuity $l$ of this relationship to represent the passage from intraday to infraday return intervals.

With the third formulation we relay on the data to determine without theoretical constraints what is the empirical law characterizing the volatility evolution through measurement intervals.

We can now use a sequence of $n$ observed unit-interval returns to estimate the variances for different return intervals $(j=1,2, \cdots, k)$ and assume that this sequence is of sufficient length to allow $g_{k}=1$. Given Equation (2') we can then derive the price adjustment coefficients $g_{j}$ if we impose some structure for the noise and intrinsic variance components.

The assumption in Damodaran [9] was that the two components could be written as functions of the covariance and variance in k-interval returns. But this is just a matter of convenience, the model offers no theoretical support for this choice. We retain only partially this hypothesis assuming the intrinsic variance to be function of the k-interval variance while the noise component depends from all the auto-covariances in the infraday return intervals. The reason is that while the choice of the $\mathrm{k}$ interval variance is innocuous and easily interchangeable given a clear association between volatility and time, this is untrue for the covariances that change in a manner unpredictable through time with large swings even from positive to negative values and vice-versa. Using the average auto-covariance over all infraday intervals we minimize the effect on the results obtaining more stable $g_{j}$ 's estimates. Writing the noise and intrinsic variance components as

$$
\begin{gathered}
\sigma_{i}^{2}=-\overline{\operatorname{Cov}\left(R_{i, j t}, R_{i, j t-1}\right)} \quad l<j \leq k \\
v^{2}=\frac{\operatorname{Var}\left(R_{i, k t}\right)+2 \overline{\operatorname{Cov}\left(R_{i, j t}, R_{i, j t-1}\right)}}{k}
\end{gathered}
$$

On the base of Equation (2') we can calculate for each interval $j$, the difference between the variance in $j$-interval returns and the equivalent variance in $k$-interval returns. Substituting for $v^{2}$ and $\sigma^{2}$ and solving through for $g_{\text {; }}$, we get
Equation (5).

In theory (5) could be used to estimate the speed of adjustment for return intervals until $j=k-1$, with only the information available in the time series of unit-interval returns data. In practice given that unit-interval returns of intraday frequency do not contain information with respect to the overnight returns we need an additional data source that could be represented by the daily stock returns.

\section{Estimation and Results}

\subsection{Data Sample and Methodological Choices}

To estimate the speed of price adjustment, we use 5 minutes as unit-interval from July 4, 1995 to May 30, 1997. The sample includes the index of the 30 most important Italian stocks (MIB30), the futures contract on this index (FIB30), all the firms included in the MIB30 (for the whole sample period or partially) as well as the biggest firms not included in this index. The final sample is composed of 58 stocks listed on the Italian Stock Exchange.

The primary reason for the sample size and the criterion for inclusion was the availability of data combined with enough liquidity for each stock. We use all returns from opening to close $(10$ a.m. to 17 p.m. for the stock market and 9.30 a.m. 17.30 p.m. for the futures market) and the daily returns to estimate for each stock, the index and the futures, the variances with return frequencies ranging from five minutes to ten days.

We calculate returns and variances over non-overlapping periods and estimate the price adjustment coefficients at intervals of five, fifteen, thirty, sixty minutes, two, four, and eight hours and at daily frequencies from one to ten days. The first empirical problem to solve is related to the relationship between time and volatility. Using only daily returns a linear approximation could be reasonable but not with the inclusion of intraday returns.

The plot in the Figure 1 below shows the average stock volatility for the intraday return intervals. As can be seen a linear relationship is acceptable as a first approximation only for the intervals between two and eight

$$
g_{i, j}=\frac{2\left[\operatorname{Var}\left(R_{i, j t}\right) / f(j)+\overline{\operatorname{Cov}\left(R_{i, j t}, R_{i, j t-1}\right)} / f(j)\right]}{\operatorname{Var}\left(R_{i, j t}\right) / f(j)+\operatorname{Var}\left(R_{i, k t}\right) / k+2 \overline{\operatorname{Cov}\left(R_{i, j t}, R_{i, j t-1}\right)} / k}
$$


hours, the inclusion of smaller or greater measurement intervals (as the daily interval with its overnight effect) has a severe impact on the linearity of the relationship.

Three other figures not included here but available upon request show the empirical relation that exists between volatility and measurement interval for the futures, the stock index and the single stocks. In this last case the average empirical law as been estimated using the observed variances for each stock in every return interval.

The conclusion is that a linear relationship does a good job for return intervals ranging from one to nine days and perhaps in some intraday range for the futures and the stock index but overall it is a poor approximation of the true relation that seems to exist between time and volatility. This result is particularly true looking at single stocks.

\subsection{Adjustment Coefficients Estimates}

To measure the impact of this methodological choice on the adjustment coefficients we present three series of results using: a) a linear relation between intrinsic variance and time; b) a linear relation but with a flat step going from the eight-hours to one-day return intervals; c) the empirical relationships. The cross-sectional average of the adjustment coefficients for all stocks in our sample, as well as the coefficients for the index and index futures are reported in Table $\mathbf{1}$.

From the results we can draw some interesting observations. First, there seems that the form of the relation ship time-volatility has a strong effect on the estimates, even if as could be expected the differences between the three sets of results decay exponentially and are almost zero after the eight hours interval. Second, the adjustment coefficients estimated for the index and the futures contract suggest strong overshooting effects over the smaller measurement intervals that only after three days (four days for the index) of continuous trading are reabsorbed. This finding is consistent with herding behavior and psychological overshooting models. Third, the average cross-sectional coefficients for the 58 stocks displays even more interesting properties, as they suggest diver-

Average Stock Volatility and Calendar Time in the Intraday Intervals

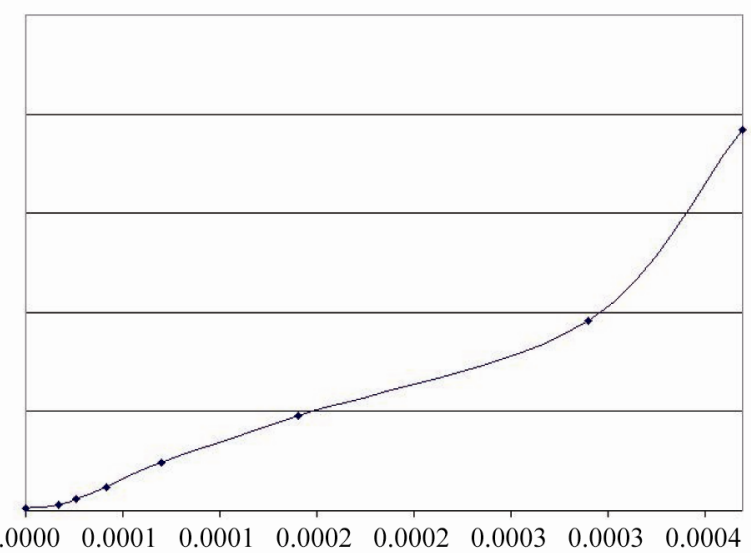

Figure 1. Average volatility for 58 securities in the intraday return intervals. Period 1995:7-1997:5.

Table 1. Speed of price adjustment: 1995/7 to 1997/5. Cross sectional averages, index and index futures coefficients for seventeen return intervals ranging from five minutes to ten days.

\begin{tabular}{|c|c|c|c|c|c|c|c|c|c|}
\hline Interval & stocks & mib30 & fib30 & stocks & mib30 & fib30 & stocks & mib30 & fib30 \\
\hline 5 & -9.9376 & 25.4676 & 15.525 & -8.0501 & 15.2178 & 8.8659 & -4.2434 & 18.9577 & 12.3483 \\
\hline $15^{\prime}$ & -3.6171 & 9.6901 & 6.0333 & -2.8442 & 5.6918 & 3.436 & -1.7994 & 7.374 & 4.8174 \\
\hline $30 ’$ & -1.6365 & 5.3059 & 3.612 & -1.2941 & 3.1873 & 2.0716 & -1.016 & 3.9234 & 2.8557 \\
\hline 1 hour & -0.4495 & 3.3333 & 2.4242 & -0.3915 & 1.9947 & 1.4041 & -0.3672 & 2.4766 & 1.8909 \\
\hline 2 hours & 0.386 & 2.3333 & 1.854 & 0.1917 & 1.3926 & 1.0894 & 0.2101 & 1.7395 & 1.4186 \\
\hline 8 hours & 1.1559 & 1.589 & 1.4927 & 0.7374 & 0.9596 & 0.9144 & 0.8459 & 1.1673 & 1.0843 \\
\hline 1 day & 0.8537 & 0.9623 & 0.9413 & 0.8537 & 0.9623 & 0.9413 & 0.8732 & 1.1662 & 1.0791 \\
\hline 2 days & 0.9572 & 0.9135 & 0.8824 & 0.9572 & 0.9135 & 0.8824 & 0.9644 & 1.072 & 1.0382 \\
\hline 3 days & 0.9999 & 0.9192 & 0.8936 & 0.9999 & 0.9192 & 0.8936 & 0.9862 & 1.0403 & 1.0218 \\
\hline 4 days & 0.9817 & 0.9253 & 0.9096 & 0.9817 & 0.9253 & 0.9096 & 0.9956 & 1.0257 & 1.0137 \\
\hline 6 days & 1.0377 & 0.8613 & 0.8312 & 1.0377 & 0.8613 & 0.8312 & 1.0182 & 1.0158 & 1.0091 \\
\hline 7 days & 1.0357 & 0.8662 & 0.8456 & 1.0357 & 0.8662 & 0.8456 & 1.0188 & 1.0114 & 1.0064 \\
\hline 8 days & 1.0211 & 0.9059 & 0.8885 & 1.0211 & 0.9059 & 0.8885 & 1.0139 & 1.0066 & 1.0038 \\
\hline 9 days & 1.0465 & 0.9514 & 0.9519 & 1.0465 & 0.9514 & 0.9519 & 1.0003 & 1.0029 & 1.0015 \\
\hline 10 days & 1 & 1 & 1 & 1 & 1 & 1 & 1 & 1 & 1 \\
\hline
\end{tabular}


gent movements from value within 60 minutes documented by negative values for the price adjustment coefficients. For intervals of more than one hour there is a lagged process of incorporation of the new information in the stock prices and the average coefficient is positive, going from 0.210 in the 60 minutes interval to 0.986 for the three-day returns. Last, in all cases the adjustment of security prices is almost completed between three and five days of trading, this is true for the index and the futures but also for every single stock.

The results in Table $\mathbf{1}$ are consistent with a market that adjusts slowly to new information, in agreement with the findings in Damodaran [9], Patell-Wolfson [3], and Hasbrouck-Lo [4] even if the adjustment process is not "linear", as it may result in very short term overshooting and divergence from equilibrium. Very short here refers to periods on the order of five minutes to few hours of trading. What about individual firms? Given that the speed of adjustment is a function of market-wide and firm-specific information, we should find significant differences among stocks related for instance to the inclusion of a stock in the index, as it is likely that the futures trading has significant feedback effects on the stock market, cfr. Tang [15] and Tang-Lui [16]. Size can also be important, but as the single stocks are included in the MIB30 on the base of size and trading the effect of this variable could be intermingled with the previous one. A similar conclusion is possible for other measures of the quality and amount of information as volume of trading or other liquidity proxies. A graphic analysis non included here shows the dispersion across securities and through return intervals for the estimated adjustment coefficients. We see a rapid incorporation of new information in prices for all stocks but it is noteworthy that the variability in the speed of adjustment is higher as the measurement interval is lessened. But a careful analysis of the results shows that there are significant regularities in the coefficients. Average adjustment coefficients for firms classified as included for the entire sample period, never included or partially included in the index of the 30 most important Italian stocks (MIB30) show that the inclusion in the index seems to be a relevant factor influencing the measured adjustment coefficients. The MIB30 stocks display the strongest movements away from value up to intervals of two hours, while the adjustment of the no-index stocks is almost zero in the five minutes interval but after that converges quickly to one. For the stocks included in the index the price adjustment is only 21 percent after four hours, and reaches the 80 percent only after one day of trading. This finding may seem a bit surprising but we should remember two facts. The first one, is that the higher liquidity induced also by the trading in the futures contract increases the volatility in the underlying stocks. The gain in efficiency related to the creation of a futures contract has to be paid in some way. A complete psychological model of price formation should account for trial and error in the trading process and learning as prices incorporate new information to reach their underlying value. This is likely to be reflected primarily in the prices of the most liquid stocks where is concentrated the activity of traders and analysts. Second, the nontrading has subtle effects on the way single stock prices adjust to value. The trading in the biggest stocks is really continuous while it is a step process for the other stocks for well known reasons related to liquidity, cost of trading, interest of institutional and other traders as well as analysts following. The smaller stocks and, in general, the stocks not included in an index underlying a futures contract are then likely to be "followers", i.e. stocks that incorporate new information after the fact. This does not necessarily imply that their price has a slower speed of adjustment with respect to the big stocks, paradoxically the high transaction costs (bid-ask spread and price impact of trading) and a low liquidity may result in a speedy adjustment process. What we mean is that the cost of errors is too high in a small stock transaction and (unless we are talking about a piece of firm-specific information), this induces the traders to concentrate their activity on the stock index futures or in the liquid underlying stocks. In these two market segments the costs are low, the liquidity is high and there is plenty of room for learning and reverse a trade in case of errors (overshooting or misinterpretation of a piece of information). This could explain why the firms not included in the MIB30 seem to adjust more quickly in the intraday intervals and why the big stocks display some evidence of movements away from equilibrium for intervals up to two hours.

\subsection{Results on Speed of Adjustment and Firm Characteristics}

The results thus far are consistent with individual stocks adjusting to market-wide and firm-specific news on the base of characteristics as liquidity, size, inclusion in the index underlying a futures, trading intensity and volume of trading. To substantiate this hypothesis we present in Table 2 the parameter estimates from regressions relating price adjustment coefficients and firm-specific factors. The proxy for size is represented from the log of capitalization at the end of our sample period, the volume of trading is simply the average value of transactions in every five-minutes interval for each single stock. We measure the intensity in the trading process as the percent of five-minutes intervals with a recorded transaction in that stock. A dummy (D30) captures the effect of inclusion in the MIB30, while another dummy, BIG6, 
Table 2. Price adjustment coefficients and individual stocks characteristics. (a) Results for the relationship between 5-minutes adjustment coefficients and firm specific factors such as the log of capitalization, trading intensity (\% of unit-intervals with a recorded transaction), volume of trading (average value of transactions in a unit-interval) and inclusion in the MIB30. T-stats are in parenthesis; (b) Results for the relationship between the individual stocks speed of adjustment and firm size measured as the log of capitalization in mid 1997 in every return interval from 5 minutes to 9 days.

(a)

\begin{tabular}{|c|c|c|c|c|c|c|c|}
\hline Model & Intercept & Size & Trading intensity & Volume of trading & D30 & BIG6 & Adj. $\mathrm{R}^{2}$ \\
\hline 1 & $35.33^{* *}(3.08)$ & $-4.81^{* *}(-3.49)$ & & & & & 0.16 \\
\hline 2 & $3.69(0.91)$ & & $-14.63^{*}(-2.16)$ & & & & 0.06 \\
\hline 3 & $-2.70(-1.34)$ & & & $-0.15(-1.44)$ & & & 0.02 \\
\hline 4 & $34.86^{*}(2.41)$ & $-4.74^{*}(-2.50)$ & & & $-0.24(-0.05)$ & & 0.15 \\
\hline 5 & $40.81^{* *}(2.85)$ & $-5.91^{* *}(-2.69)$ & $6.55(0.65)$ & & & & 0.15 \\
\hline 6 & $56.16^{* *}(3.80)$ & $-7.53^{* *}(-4.08)$ & & & & $14.79^{*}(2.14)$ & 0.21 \\
\hline
\end{tabular}

(b)

\begin{tabular}{cccc}
\hline Return interval & Intercept & Size & ${\text { Adj. } \mathrm{R}^{2}}$ \\
\hline $5^{\prime}$ & $35.33^{* *}(3.08)$ & $-4.813^{* *}(-3.49)$ & 0.16 \\
$15^{\prime *}$ & $19.82^{* *}(3.27)$ & $-2.630^{* *}(-3.60)$ & 0.17 \\
$30^{\prime}$ & $14.90^{* *}(3.34)$ & $-1.936^{* *}(-3.60)$ & 0.17 \\
1 hour & $10.70^{* *}(3.45)$ & $-1.346^{* *}(-3.60)$ & 0.17 \\
2 hours & $7.07^{* *}(3.69)$ & $-0.834^{* *}(-3.62)$ & 0.17 \\
4 hours & $4.25^{* *}(4.24)$ & $-0.443^{* *}(-3.67)$ & 0.18 \\
8 hours & $2.57^{* *}(5.46)$ & $-0.210^{* *}(-3.70)$ & 0.18 \\
1 day & $1.84^{* *}(4.78)$ & $-0.118^{*}(-2.54)$ & 0.09 \\
2 days & $1.28^{* *}(8.08)$ & $-0.039^{*}(-2.03)$ & 0.05 \\
3 days & $1.07^{* *}(8.87)$ & $-0.010(-0.71)$ & 0 \\
4 days & $0.97^{* *}(8.98)$ & $0.003(0.21)$ & 0 \\
5 days & $0.89^{* *}(10.14)$ & $0.013(1.22)$ & 0.01 \\
6 days & $0.78^{* *}(7.30)$ & $0.029^{*}(2.24)$ & 0.07 \\
7 days & $0.73^{* *}(7.42)$ & $0.035^{* *}(2.96)$ & 0.12 \\
8 days & $0.78^{* *}(7.66)$ & $0.028^{*}(2.26)$ & 0.07 \\
9 days & $0.83^{* *}(6.66)$ & $0.021(1.43)$ & 0.02 \\
\hline
\end{tabular}

Superscripts ${ }^{* *},{ }^{*}$, and represent significance at the $1 \%, 5 \%$ and $10 \%$ level.

singles out the six biggest Italian stocks (Generali, Fiat, Telecom, Eni, Tim, Stet).

Table 2(a) shows the results with the five-minutes adjustment coefficients as dependent variable. The volume of trading per se seems unrelated to the speed of adjustment in the unit-interval, while the effect of the variable measuring trading intensity becomes not significant when we add size to the regression. This is probably due to the positive correlation existing between size and this variable. Size is always significant and its beta is negative so that an increase in size is associated with a reduction in the adjustment coefficient. In terms of unit-interval $g_{i}$ 's this implies more cases of overshooting between small stocks and an increase in the frequency of divergent movements as size grows.

The dummy for inclusion in the MIB30 is not significant when we control for size but the dummy for the six most important stocks retains its significance and this has the effect of reversing the impact of size on the adjustment coefficient for high levels of capitalization.

Table 2(b) presents the regression results for the relationship between speed of adjustment and stock size in each return interval. The results in Table 2(b) confirm that firm size is strongly related to the measured speed of adjustment.

The relationship between adjustment coefficients and the $\log$ of capitalization is consistently negative for measurement intervals ranging from five minutes to three days and statistically significant but for the last interval. The direction of this relationship is reversed for return intervals of four days or more, but in this case size is significant only for the intervals from six to eight days.

The results presented in Table 2 are based on the adjustment coefficients estimated using the empirical relationship between time and volatility but qualitatively the results are the same even if we use the other two forms 
of the relationship.

Overall our results support the proposition that stock prices adjust slowly to new information but in a different manner for small and big firms and this is reflected in a highly significant relation between adjustment coefficients and stock size. The inclusion in the MIB30 index does not seem to be a relevant factor but this is the result of two facts. First, only the biggest stocks are included in the index, adding size as explanatory variable is likely to dim any effect related to a dummy controlling for the participation in the index. Second, among the big firms the trading is highly concentrated in few stocks and is not by chance that in Table 2(a) a dummy like BIG6 is significant even when the MIB30 dummy is added to model 6 (not shown). These six stocks are the core of every portfolio whose aim is to replicate the index and are necessary to implement any strategy requiring trading in the futures and the underlying market.

\section{Conclusions}

The degree of efficiency in the stock and futures markets can be measured by the speed with which prices adjust to incorporate new information. This process may be slow with prices that take time to reflect value changes or very speedy. It is also possible that in very short intervals or in the long period prices display patterns that lead away from equilibrium (at least temporarily) or give rise to under and overreaction phenomena.

This paper adapts the model developed in AmihudMendelson [8] and Damodaran [9] to consider jointly intraday and infraday data. The speed of adjustment is estimated as function of the variances in different return intervals from five minutes to ten days, as well as the covariances in the infraday intervals. The approach is then applied to the Italian index (MIB30) and index futures (FIB30), and to a sample of the most important stocks listed in this market.

We show that the assumptions about the form of the relationship between return volatility and time are critical for the measured adjustment coefficients, the hypothesis of linearity cannot be accepted using jointly intraday and infraday returns as the resulting estimates are grossly inflated for the smaller measurement intervals. We find evidence that prices adjust slowly to new information, three to five days of trading are necessary to complete the adjustment and this is true for the index futures but also on average for each individual stock. We also find evidence that there is no simple intraday adjustment process, the futures seems to overreact for small return intervals, while on average the individual stocks diverge from value for intervals up to two hours and then show a pattern of lagged adjustment.
There are peculiar regularities in the price adjustment of single stocks and the firms included in the index underlying the futures behave differently from the others. The analysis of the relationship between adjustment coefficients and firm characteristics confirms that size is strongly related to the measured speed of adjustment for most of the measurement intervals

\section{References}

[1] K. Daniel, D. Hirshleifer and A. Subrahmanyam, "Investor Psychology and Security Market Under- and Overreactions," Journal of Finance, Vol. 53, No. 6, 1998, pp. 1839-1885. doi:10.1111/0022-1082.00077

[2] E. F. Fama, "Market Efficiency, Long Term Returns and Behavioral Finance,” Journal of Financial Economics, Vol. 49, No. 3, 1998, pp. 283-306. doi:10.1016/S0304-405X(98)00026-9

[3] J. M. Patell and M. A. Wolfson, "The Intraday Speed of Price Adjustment of Stock Prices to Earnings and Dividend Announcements," Journal of Financial Economics, Vol. 13, No. 2, 1984, pp. 223-252. doi:10.1016/0304-405X(84)90024-2

[4] J. Hasbrouck and T. Ho, “Order Arrival, Quote Behavior and the Return-Generating Process,” Journal of Finance, Vol. 42, No. 4, 1987, pp. 1035-1049. doi:10.2307/2328305

[5] K. Garbade and W. Silber, "Structural Organization of Secondary Markets: Clearing Frequency, Dealer Activity and Liquidity Risk,” Journal of Finance, Vol. 34, No. 3, 1979, pp. 577-593. doi:10.2307/2327427

[6] K. Garbade and W. Silber, "Price Movement and Price Discovery in Futures and Cash Markets," Review of Economics and Statistics, Vol. 65, No. 2, 1983, pp. 289297. doi:10.2307/1924495

[7] B. Goldman and A. Beja, "Market Prices vs. Equilibrium Prices: Return's Variance, Serial Correlation, and the Role of the Specialist," Journal of Finance, Vol. 34, No. 3, 1979, pp. 595-607. doi:10.2307/2327428

[8] Y. Amihud, and H. Mendelson, "Index and Index-Futures Returns," Journal of Accounting, Auditing \& Finance, Vol. 4, No. 2, 1989, pp. 415-431.

[9] A. Damodaran, "A Simple Measure of Price Adjustment Coefficients,” Journal of Finance, Vol. 48, No. 1, 1993, pp. 387-400. doi:10.2307/2328896

[10] N. Brisley and M. Theobald, “A Simple Measure of Price Adjustment Coefficients: A Correction,” Journal of $\mathrm{Fi}$ nance, Vol. 51, No. 1, 1996, pp. 381-382. doi:10.2307/2329314

[11] W. F. M. DeBondt and R. H. Thaler, "Does the Stock Market Overreact?” Journal of Finance, Vol. 40, No. 3, 1985, pp. 793-808. doi:10.2307/2327804

[12] Y. Amihud and H. Mendelson, "Trading Mechanisms and Stock Returns: An Empirical Investigation,” Journal of Finance, Vol. 42, No. 3, 1987, pp. 533-553. doi: $10.2307 / 2328369$ 
[13] Y. Amihud, H. Mendelson and M. Murgia, "Stock Market Microstructure and Return Volatility: Evidence from Italy," Journal of Banking and Finance, Vol. 14, No. 2-3, 1990, pp. 423-440. doi:10.1016/0378-4266(90)90057-9

[14] P. Gottardo, "Dinamica dei Rendimenti e relazioni leadlag fra il FIB30 e l'indice MIB30," Studi e Note di Economia, Vol. 3, No. 3, 1998, pp. 69-103.

[15] G. Y. N. Tang, "Return Volatilities of Stock Index Fu- tures in Hong Kong: Trading vs Non-Trading Periods," Journal of Derivatives, Vol. 4, No. 1, 1996, pp. 55-62. doi:10.3905/jod.1996.407961

[16] G. Y. N. Tang and D. T. W. Lui, "Intraday and Intraweek Volatility Patterns of Hang Seng Index and Index Futures, and a Test of the Wait-To-Trade Hypothesis," PacificBasin Finance Journal, Vol. 10, No. 4, 2002, pp. 475-495. doi:10.1016/S0927-538X(02)00069-0 